\title{
AN INTENSIVE COURSE OF TREATMENT FOR SYPHILIS, WITH SPECIAL REFER- ENCE TO ITS TOXIC EFFECTS
}

By ERNEST E. PREBBLE, M.D., Ch.B. (U. Liverpool), M.R.C.S. (Eng.), L.R.C.P.(Lond.); Senior Assist. V.D. Med. Officer, Seamen's Dispensary, Liverpool.

THE immediate objects of the investigation herein described are two-fold :-

I. Therapeutic efficiency.

2. Toxic effects and comparison with the more usual courses of treatment for syphilis.

It is also intended to put forward the claims of this intensive course of treatment of syphilis in all its stages instead of the more usually accepted course of treatment as was practised at Rochester Row Hospital, London, and in a modified form by many other syphilologists throughout this country at the present time.

\section{Early Pioneers of the Intensive Course OF TREATMENT}

(I) Fildes and Parnell 1.-These two workers conducted their investigations at the Royal Naval Hospital, Haslar, during the years I9I7-I9. Their course, which they called the No. I course, consisted in the giving of six doses of "9I4" at intervals of three days, each dose being $0.45 \mathrm{gm}$. of the drug. For statistical purposes the cases were graded into A, B, C and D cases.

An " A " case was a man with an inoculation lesion in whom the Wassermann reaction had not yet become positive.

A " B " case was a man with an inoculation lesion or with a history of an inoculation lesion, but with no other outward signs or history of general infection except glandular enlargement, and a positive W.R. up to and including eighteen months from the date of infection.

A " C" case was a man with outward signs or history of general infection including a positive W.R. up to and including eighteen months from the date of infection. 


\section{BRITISH JOURNAL OF VENEREAL DISEASES}

A " D " case was a man with or without symptoms or signs over eighteen months from the date of infection.

It will be seen that types $A$ and $B$ include all instances of primary syphilis and early latent syphilis or endosyphilis. C cases are acute or recent cases of secondary syphilis, but some early tertiary lesions come under this category; while D cases include not only late secondary, but tertiary and most latent infections.

Results of TREatment

\begin{tabular}{|c|c|c|c|c|c|}
\hline Type. & Total Cases. & No. Neg. & $\begin{array}{c}\text { Per cent. } \\
\text { Neg. }\end{array}$ & No. Pos. & $\begin{array}{c}\text { Per cent. } \\
\text { Pos. }\end{array}$ \\
\hline A. & 44 & 44 & I00 & 0 & 0 \\
\hline B. & I28 & 98 & 79 & 30 & $2 \mathrm{I}$ \\
\hline C. & I44 & I02 & $7 \mathrm{I}$ & 42 & 29 \\
\hline D. & 29 & 8 & 28 & $2 \mathrm{I}$ & 72 \\
\hline
\end{tabular}

It is important to bear in mind that these workers conducted this research during the transition period and before the advent of bismuth. Following on this work, Fildes and Parnell devised a second course of treatment which was even more effective therapeutically. This course was known as the No. 2 course, and consisted in giving, intravenous injections of " $9 \mathrm{I} 4$ " at four-daily intervals, the doses being $0.45 \mathrm{gm}$. and $0.6 \mathrm{gm}$. alternately. A total of $4.2 \mathrm{gm}$. of the arsenical was given and constituted one course.

(2) A.O. Ross ${ }^{2},{ }^{3},{ }^{4},{ }^{5}$.-Following on the work of Fildes and Parnell the next syphilologist to carry on this scheme, at any rate on a large scale, was A. O. Ross at the Seamen's Dispensary, Liverpool. The writer has collected a large series of results of treatment carried out at this clinic during the years I926-3I. Whereas in the case of the previous workers the patients under treatment were in the Royal Naval Hospital at Haslar, and in consequence were regular in attendance and able to follow out the complete treatment, in the case of the Seamen's Dispensary we meet a different set of conditions. Here one is dealing with a civilian population, for the most part 


\section{COURSE OF TREATMENT FOR SYPHILIS}

seafaring, and consequently defaulters are many. If the numbers of cases appear somewhat small, it must be remembered that only those cases completing at least one course of treatment and returning for a subsequent Wassermann are included in this survey.

\section{The Scheme of Treatment}

In the series under review the classification used by Colonel Harrison in the Special Report Series (the M.R.C. No. I32) has been used, namely :-

A. Sero-negative primary cases.

B. Sero-positive primary cases.

C. Early secondary cases with roseolar and/or lenticulopapular eruptions and perhaps mucous membrane lesions.

D. Cases with infections of more than six months' duration and with positive W.R., or with active signs of disease, or both.

The foundation of the method of treatment to be described is that of Fildes and Parnell (M.R.C., S.R.S., No. 23), where the No. 2 course has been extended in most instances to give an arsenobenzol dosage of $5.7 \mathrm{gm}$. and concurrent bismuth administration to the extent of $3.6 \mathrm{gm}$. has been introduced. The course is as follows :-

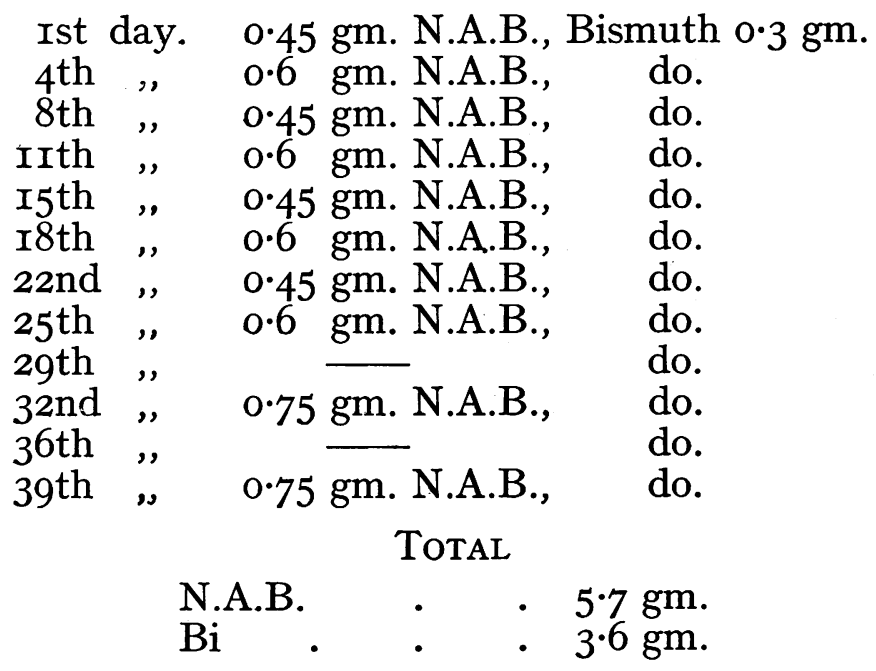

Novarsenobillon (Messrs. May and Baker Ltd.) has been used in every case. Where similar preparations have been employed, toxic reactions have followed in greater 


\section{BRITISH JOURNAL OF VENEREAL DISEASES}

proportion and their use has been abandoned. Bismuth in various forms has been used, namely, bismostab, bisoxyl, bisglucol, collosol bismuth and bivatol, and it would appear that it is of no importance to the therapeutic results which preparation is used. The chief desideratum in the use of a good bismuth preparation is the absence of local pain following intramuscular injection.

In Fildes and Parnell's series a second course of N.A.B. was not given unless there was a clinical or serological relapse, but it has always been the case at the Seamen's Dispensary to repeat the course at the end of three months and again at the end of nine months after completion of the first course. This treatment is followed out in all stages of the disease except in those cases exhibiting advanced cardio-vascular disease, renal disease, hepatic disease or in neuro-syphilis.

It will be seen that this course of treatment occupies 39 days as against 92 days in the other and more usual course, and as against I20 days in the course used at St. Thomas's Hospital, London, since 22.2.28. ${ }^{6}$ The shortness of this course is of great value, especially in the case of seafarers, who can ill afford to remain ashore for protracted periods of time. The interval of three months between the first and second course allows the seafarer to return to sea with the certainty, as will be shown later, that he will not have a clinical or Wassermann relapse during that time. From an economic point of view this great saving of time spent ashore is very valuable. In certain cases where the voyage lasts four and a half months, that length of time is allowed between the first and second courses.

For purposes of comparison I am including a copy of the course as used, until February, I928, at St. Thomas's Hospital, London. Subsequent to this date a modified course was used, but in no published cases were intravenous injections given bi-weekly.

(3) Other Workers.-The literature on the intensive course of treatment with "9I4" is not at all extensive, and no figures are given to support the various schemes adopted. Amongst those who have used an intensive course may be mentioned Labbé and Gendron, ${ }^{7}$ Teodosijevits, ${ }^{8} \mathrm{~W}$. Kerl, ${ }^{9}$ E. Hoffmann and Armuzzi, ${ }^{10,}{ }^{11}$ and Baketel $\mathbf{1 2}$ in the United States of America, who quotes several workers in that country using an intensive course 


\section{COURSE OF TREATMENT FOR SYPHILIS}

with modifications. In none of these cases does the course correspond to the one herein described which is a direct link with that originally used by Fildes and Parnell.

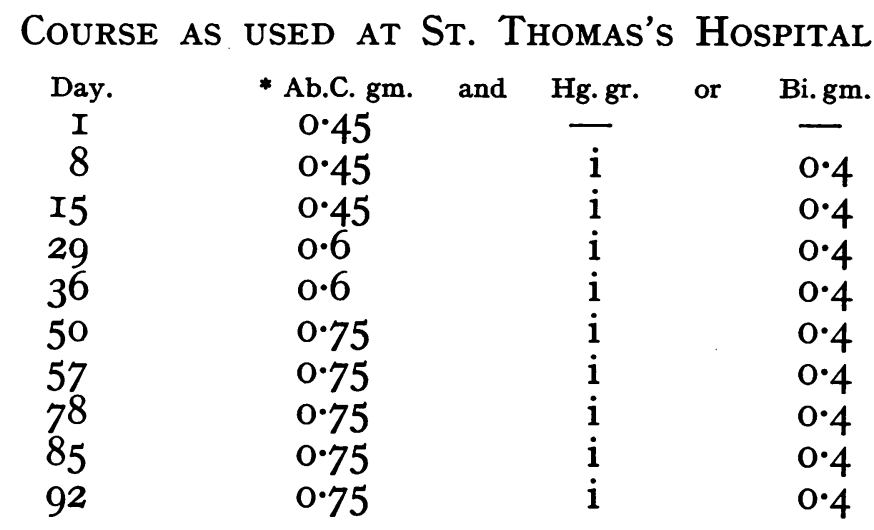
day.

Potassium iodide is given from the $57^{\text {th }}$ to the 78 th

Total : 6.2 gm. Ab.C. and $9 \mathrm{gr}$. $\mathrm{Hg}$. or $3.6 \mathrm{gm}$. Bi.

Results of Treatment at the Seamen's Dispensary

For the purposes of this investigation some 2,064 cases of syphilis were tabulated. Of this number 399 completed at least one course of treatment and returned for a second course and a Wassermann reaction, or a Wassermann reaction only in a few cases. Many cases completed one course of treatment, but failed to return for a subsequent Wassermann test. The remaining cases either failed to complete one course or were transferred to other clinics and therefore do not enter into this article. Of the 399 cases which fulfilled the necessary conditions, 296 attended regularly for treatment and ro3 completed a full course, but with some irregularity in attendance for treatment. At the outset it is important to make it quite clear that for complete success absolute regularity is of paramount importance, quite small deviations from the normal course adversely affecting the results.

If we now analyse these results we obtain a very interesting set of figures.

\footnotetext{
* Ab.C $=$ Arsenobenzine compounds.
}

v.D. 


\section{BRITISH JOURNAL OF VENEREAL DISEASES \\ - \\ Results of Treatment}

Table of Results Obtained

(I) Regular

\begin{tabular}{|c|c|c|c|c|c|}
\hline Type. & Total Cases. & No. Neg. & $\begin{array}{c}\text { Per cent. } \\
\text { Neg. }\end{array}$ & No. Pos. & $\begin{array}{c}\text { Per cent. } \\
\text { Pos. }\end{array}$ \\
\hline A. & 92 & 92 & I00 & 0 & 0 \\
\hline B. & 77 & 77 & I00 & 0 & 0 \\
\hline C. & 33 & 33 & I00 & 0 & 0 \\
\hline D. & 82 & 47 & 57 & 35 & 43 \\
\hline
\end{tabular}

(2) Irregular

\begin{tabular}{|c|c|c|c|c|c|}
\hline Type. & Total Cases. & No. Neg. & $\begin{array}{c}\text { Per cent. } \\
\text { Neg. }\end{array}$ & No. Pos. & $\begin{array}{c}\text { Per cent. } \\
\text { Pos. }\end{array}$ \\
\hline A. & 24 & I7 & 7 I & 7 & 29 \\
\hline B. & 32 & II & 34 & 2 I & 66 \\
\hline C. & 9 & 5 & 56 & 4 & 44 \\
\hline D. & 34 & I2 & 35 & 22 & 65 \\
\hline
\end{tabular}

These results show that the successes are roo per cent. in all regularly treated $\mathrm{A}, \mathrm{B}$, and $\mathrm{C}$ cases, and as high as 57 per cent. in $\mathrm{D}$ cases. It is important to bear in mind that amongst the cases of irregularly treated syphilis only those cases are included which receive approximately the same amount of treatment as the regular ones. In addition the irregularity only slightly deviates from the normal bi-weekly course.

The following table of results is given by way of a comparison. The figures are those obtained from St. Thomas's Hospital, London, in the clinic supervised by Colonel L. W. Harrison and universally recognised as the standard treatment centre in England. 
COURSE OF TREATMENT FOR SYPHILIS

\begin{tabular}{|c|c|c|c|c|c|}
\hline Type. & Total Cases. & No. Neg. & $\begin{array}{c}\text { Per cent. } \\
\text { Neg. }\end{array}$ & No. Pos. & $\begin{array}{c}\text { Per cent. } \\
\text { Pos. }\end{array}$ \\
\hline A. & II5 & I09 & 95 & 6 & 5 \\
\hline B. & I20 & I04 & 87 & I6 & I3 \\
\hline C. & I67 & III & 66 & 56 & 34 \\
\hline D. & 538 & 83 & I5 & 455 & 85 \\
\hline
\end{tabular}

This table shows the efficacy of the first course of treatment and is in every way comparable to the table given previously (p. I20) for the Seamen's Dispensary, Liverpool. In Colonel Harrison's cases the blood is taken for the second time to observe the results of treatment at a time varying from the fourth to the fifth month after commencement of treatment. At the Seamen's Dispensary the second blood is taken immediately prior to the second course of treatment, i.e., about four and a half months after the first blood test is taken. There is no question as to the system which gives the better results.

In the case of those infections which are D cases it is particularly striking. Even in the irregularly treated cases the proportion of negative Wassermann reactions is very much higher. It would appear that smaller doses of N.A.B. given at more frequent intervals act much more efficiently than slightly larger doses given at weekly intervals.

The Wassermann used is that carried out at the Liverpool City Laboratories, using Colonel Harrison's technique, with the exception that horse serum as hæmolytic amboceptor is used, manufactured by Messrs. Burroughs and Welcome.

\section{INTOXICATIONS}

In putting forward any scheme for the treatment of syphilis it is very necessary to consider its disadvantages as well as its advantages.

It is readily acknowledged that the drugs of the arsenobenzol series are liable to produce certain toxic effects due to the arsenic content. Arsenic is a drug 


\section{BRITISH JOURNAL OF VENEREAL DISEASES}

which is badly tolerated by some patients who exhibit certain well-defined symptoms of intolerance when the administration of the drug is persisted with. The most important of these toxic effects may be summarised under three main headings :-
(i.) Erythema.
(ii.) Dermatitis.
(iii.) Jaundice.

Let us consider each separately in its relation to this present course of treatment.

(i.) Erythema.-This toxic reaction manifests itself as an erythematous eruption closely allied to a scarlatinal rash. In many instances it also closely resembles the reaction found in cases of so-called protein-shock. It is preceded by an itching of the skin which gradually passes away as the rash fully develops. The rash is almost invariably universal in distribution. In the present course of treatment it was found that it most frequently occurred after the third or fourth injections of N.A.B. It is of a transient nature, and provided the condition is recognised and further arsenical treatment avoided it almost always clears rapidly.

(ii.) Dermatitis.-This complication is a much more serious one and can lead to fatal results, although in the present series we have not had such an unfortunate occurrence. It varies considerably in severity from a branny desquamation over a small area of cutaneous surface to a fulminating exfoliative dermatitis involving large areas of the body. This condition seldom occurs prior to the sixth injection.

(iii.) Jaundice.-This complication again is of a more serious nature than a simple erythema. It is usually considered to be due to a hepatitis produced by faulty excretion of arsenic. It is the intoxication which occurs latest in the course of treatment usually manifesting itself some weeks after the completion of the first course of treatment and occasionally as late as four months afterwards. In our experience it is rarely seen in the second course of treatment. Whilst certain cases undoubtedly are due to the effect on the liver of the arsenic, it appears probable that in a certain number of cases the jaundice is of an ordinary catarrhal type and would have occurred even had arsenic not been administered. The 


\section{COURSE OF TREATMENT FOR SYPHILIS}

condition was frequently seen in the pre-salvarsan days, and is often seen during treatment with bismuth alone. In addition it must be remembered that syphilitic hepatitis does occur in patients who have had no treatment at all.

The results which follow show that many cases of intoxications occurred about the same time. These would lead one to assume that some batches of the drug may be more toxic than others, and that seasonal variations in weather may also be partially responsible.

In an endeavour to cut down the number of intoxications at this clinic from June, I926, it has been the practice to dissolve the third and fourth doses of " $9 \mathrm{I}_{4}$ " in distilled water to which $0.6 \mathrm{gm}$. of pure sodium thiosulphate is added. This it will be recalled is the period at which erythema is most likely to occur. This resulted in a marked falling off in the number of such intoxications, and from November, I928, onwards it has been the practice to dissolve each dose in such a solution. Figures show that the numbers of intoxications have been materially lowered.

Certain patients are undoubtedly more liable to manifest toxic reactions than others. This is particularly the case in fair-haired people and in those troubled with seborrhœa. All toxic effects are due to faulty excretion of arsenic which varies considerably in different individuals. A test known as the Abelin reaction ${ }^{13}$ has been devised to discover whether excretion is taking place, in any particular case, at the normal rate or not. This test is carried out as a routine measure at this clinic.

A. Savulesco ${ }^{14}$ recently advocated the solution of each dose of " $9 \mathrm{I} 4$ " in 5 c.c. of a 20 per cent. solution of sodium dehydrocholate. The bile salt is believed to tone the liver and protect it against the effects of the arsenobenzene compound. So much so that the author states that, as a matter of routine, he gives a course of from 5 to $6 \mathrm{gm}$. " $9 \mathrm{I} 4$ " in the space of two or three weeks without ill effect, the individual doses being from 0.75 to $0.9 \mathrm{gm}$. given every two to five days. In our experience with this drug it was found that several patients complained of nausea and even sickness after the injection, and we reverted to the sodium thiosulphate. 


\section{BRITISH JOURNAL OF VENEREAL DISEASES}

\section{INTOXICATIONS}

\begin{tabular}{|c|c|c|c|}
\hline Total Cases. & No. of Injections. & Jaundice. & $\begin{array}{c}\text { Dermatitis and Other } \\
\text { Skin Lesions. }\end{array}$ \\
\hline 2,064 & I0,442 & 26 & $\begin{array}{c}46 \\
\text { (incl. 23 erythema) }\end{array}$ \\
\hline
\end{tabular}

These figures show a total number of 72 intoxications, but 3 cases of erythema subsequently developed jaundice, thereby reducing the total to 69 .

\section{Ratio of Complications to}

(I) Total number of cases : I in 30 .

(2) Total number of injections: $\mathrm{I}$ in $\mathrm{I} 5 \mathrm{I}$.

The results obtained by this course of treatment are very encouraging as regards regularly treated $\mathrm{A}, \mathrm{B}$ and $C$ cases. In $D$ cases it has been found that there were a few instances of subsequent Wassermann relapse. In the A, B and C groups no case has relapsed clinically or serologically provided two courses of treatment have been given, and no case has relapsed within six months after one course of treatment. The figures produced show the numbers of intoxications to be slightly higher than those obtained by syphilologists making use of the once weekly course of treatment. With the object in view of lowering the numbers of intoxications without effecting the therapeutic efficiency of the treatment a new scheme has been adopted during the past two years. In the smaller number of cases which have been treated by this method this object has been realised. I am appending figures in support of this statement which will fully bear out the claim put forward. The course is as follows:-

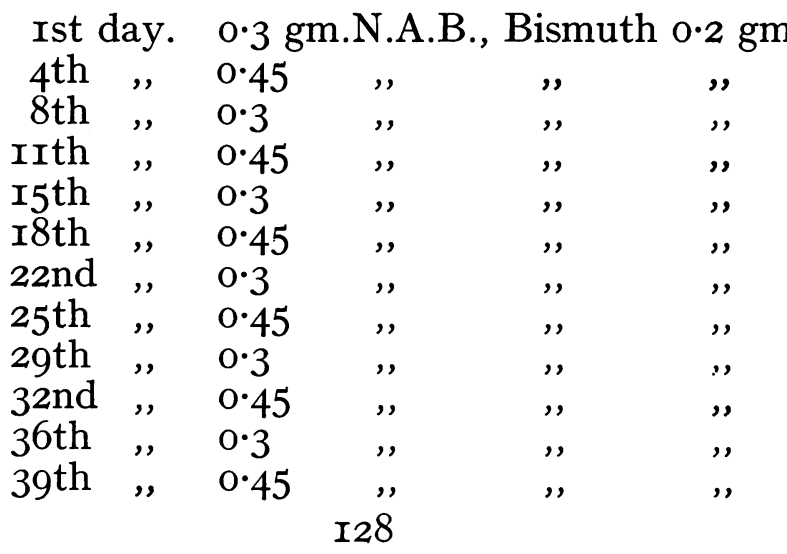




\section{COURSE OF TREATMENT FOR SYPHILIS}

This course gives a total dosage of N.A.B. of $4.5 \mathrm{gm}$. and of bismuth $2.4 \mathrm{gm}$., and is therapeutically as efficient as the previously described course and gives rise to fewer cases of intolerance. The results obtained follow.

\section{Results of Modified Course of Treatment}

689 cases have been treated with this modified course, and of this number only I3I fulfilled the necessary conditions to merit inclusion in this series. Taking the I3I cases we find that 94 cases were given an absolutely regular course of treatment, and the remaining 37 cases had the requisite amount of treatment, but were slightly irregular in attendance. The total number of injections given were 4,823 .

(I) Regular

\begin{tabular}{|c|c|c|c|c|c|}
\hline Type. & Total Cases. & Neg. & $\begin{array}{c}\text { Per cent. } \\
\text { Neg. }\end{array}$ & Pos. & $\begin{array}{c}\text { Per cent. } \\
\text { Pos. }\end{array}$ \\
\hline A. & 40 & 40 & I00 & 0 & 0 \\
\hline B. & I9 & I9 & I00 & o & 0 \\
\hline C. & I0 & I0 & I00 & 0 & 0 \\
\hline D. & 25 & I5 & 60 & IO & 40 \\
\hline
\end{tabular}

(2) Irregular

\begin{tabular}{|c|c|c|c|c|c|}
\hline Type. & Total Cases. & Neg. & $\begin{array}{c}\text { Per cent. } \\
\text { Neg. }\end{array}$ & Pos. & $\begin{array}{c}\text { Per cent. } \\
\text { Pos. }\end{array}$ \\
\hline A. & 9 & 7 & 77 & 2 & 23 \\
\hline B. & 8 & 4 & 50 & 4 & 50 \\
\hline C. & 2 & 0 & 0 & 2 & 100 \\
\hline D. & I8 & 8 & 44 & I0 & 56 \\
\hline
\end{tabular}

If these results are studied (Table I) it will be found that as before, all $\mathrm{A}, \mathrm{B}$ and $\mathrm{C}$ cases return with a negative Wassermann reaction after completion of the first course of treatment. In the $\mathrm{D}$ cases 60 per cent. return with a negative Wassermann reaction. 


\section{BRITISH JOURNAL OF VENEREAL DISEASES}

\section{INTOXICATIONS}

If we now take these 689 cases who were given a total of 4,823 injections, and study the numbers of intoxications, we find that out of this number of cases there were II cases of intolerance which were :

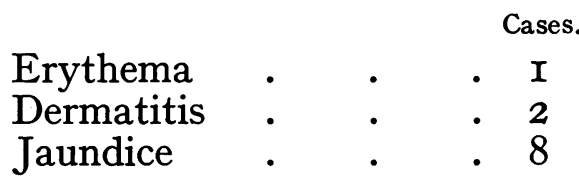

\begin{tabular}{|c|c|c|c|}
\hline Total Cases. & No. of Injections. & Jaundice. & $\begin{array}{c}\text { Dermatitis and Other } \\
\text { Skin Lesions. }\end{array}$ \\
\hline 689 & 4,823 & 8 & 3 \\
\hline
\end{tabular}

Ratio of complications to :

(I) Total number of cases : $I$ in 63

(2) Total number of injections : $\mathrm{I}$ in 438

These figures show that the incidence of complications has been reduced from I in 30 cases to $I$ in 63 cases, and from $I$ in $I 5 I$ injections to $I$ in 438 injections without in anyway decreasing the therapeutic efficiency of the treatment.

By way of comparison I am appending figures collected from various sources to show the incidence of intoxications as a result of the once weekly course of treatment.

In discussing the subject of intoxications as a result of the administration of arsenical compounds, three main types have been taken into consideration, viz., erythema, dermatitis and jaundice. In the case of the two former types, it would appear that the arsenical drug is the direct cause of the disturbance, but this has not been definitely proved in the case of jaundice. As previously mentioned, it will be seen that in the present series of cases, the patients developing jaundice did so in groups. This would lead one to suppose that seasonal variations or specially toxic samples of the drug were at any rate partially responsible. 
COURSE OF TREATMENT FOR SYPHILIS

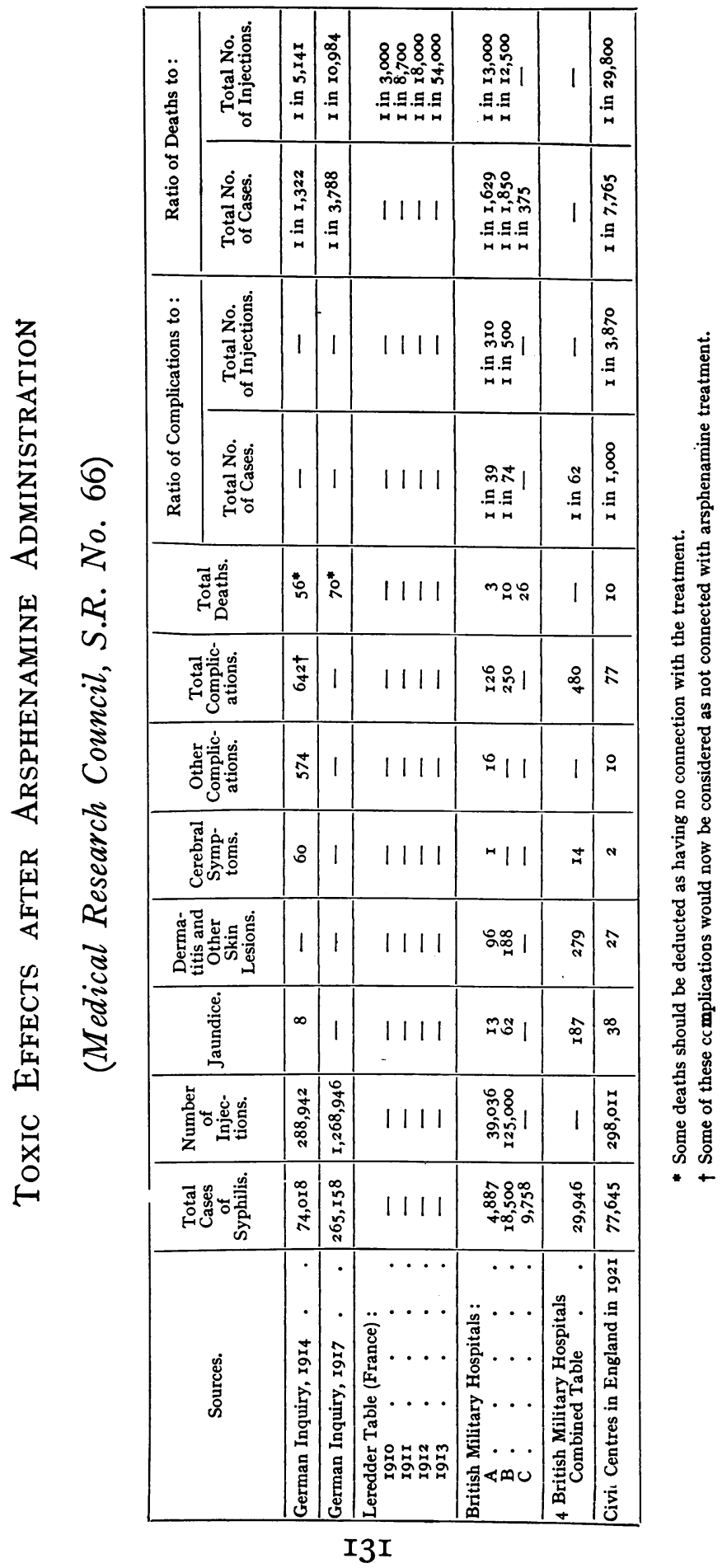




\section{BRITISH JOURNAL OF VENEREAL DISEASES}

\begin{tabular}{|c|c|c|c|}
\hline \multicolumn{4}{|c|}{ JAUNDICE } \\
\hline May I927 : & . & . & . \\
\hline August I927 & . & . & 2 \\
\hline November I927 & . & . & . \\
\hline November I928 & • & • & 2 \\
\hline February I929 & . & . & 2 \\
\hline October I929 & . & . & . \\
\hline December I929 & • & • & - \\
\hline August I930 & . & - & . \\
\hline December I930 & • & • & 2 \\
\hline January I93I & - & - & 2 \\
\hline March I93I & . & . & I \\
\hline June I93I . & . & • & 3 \\
\hline
\end{tabular}

I would therefore suggest that this latter complication might be omitted from the calculations and that only the skin manifestations be taken into consideration. The following figures would then be obtained.

\section{SeAmen's Dispensary}

First Course. -46 cases of skin complications, giving :

$I$ in 45 cases.

$I$ in 227 injections.

Second Course.-3 cases of skin complications, giving : $I$ in 229 cases.

$I$ in $I, 607$ injections.

British Military Hospitals

A. -96 cases of skin complications, giving :

$I$ in $5 \mathrm{I}$ cases.

$I$ in 406 injections.

B. $-\mathrm{I} 88$ cases of skin complications, giving :

$\mathrm{I}$ in 98 cases.

$I$ in 665 injections.

Four combined. 279 cases of skin complications, giving I in 107 cases.

In no case do these figures compare favourably with those obtained in the second course as used at the Seamen's Dispensary. 


\section{COURSE OF TREATMENT FOR SYPHILIS}

\section{SUMMARY}

The advantages of this method of treatment are therefore :-

(I) Shorter period of time required for treatment.

(2) Comparatively long intervals between courses of treatment enabling seafaring men to complete a voyage before returning for a further period of time ashore.

(3) Definite prognosis can be given in every case of primary and secondary syphilis.

(4) Excellent therapeutic effect.

(5) Accurate knowledge of probable date of the Wassermann relapse.

In conclusion I wish to express my deep appreciation to Dr. A. O. Ross for the helpful suggestions made and for advice so willingly and freely given, and also to Dr. W. M. Fraser, Medical Officer of Health for the City and Port of Liverpool for permission to publish these results.

\section{REFERENCES}

(I) Fildes and Parnell : M.R.C., Special Report Series, No. 4I, I9I9.

(2) Ross, A. O. : Proc. Imp. Soc. Hyg. Cong., I927.

(3) Ross, A. O. : Proc. Imp. Soc. Hyg. Cong., I929.

(4) Ross, A. O. : British Journal of V.D. July, I929.

(5) Ross, A. O.: Lancet, November 28th, I930.

(6) Harrison, Col. L. W. : Special Report Series, No. I32, I929.

(7) Labbe et Gendron : Bull. et Mém. Soc. Méd. d'Hôp. de Paris, I9I5-16. $3 \mathrm{~s}$ xl., I945-53.

(8) Teodosijevits: Deut. Med. Wschr., I925, LI., 608.

(9) KeRL, W. : Wien. Med.Wschr., I929, LXXIX., I223.

(Io) Hoffmann, E., and ARmuzzi : Deut. Med. Wschr., I927, LIII., $5 \mathrm{I}-3$.

(II) Hoffmann, E. : Dermat. Zeitschr., October, I930.

(I2) BAKETEL : Amer. Journ. of Syph., I924, VIII., 9I-II6.

(I3) LlOYd and LlOYD: B.J.V.D., January, I932.

(I4) Savulesco, A. : Bull. et Mém. Soc. Méd. Hôpit. de Bucarest., I930, XII., 220. 